\title{
Efetividade do uso da Fibrina Rica em Plaquetas (PRF) no levantamento de seio
}

\section{maxilar: relato de caso}

\author{
Platelet-Rich Fibrin (PRF) effectiveness in maxillary sinus lift: case report \\ Efectividad del uso de Fibrina Rica en Plaquetas (PRF) en la encuesta del seno maxilar: reporte de
}

Flávia Gouvêa Costa Tchemra

ORCID: https://orcid.org/0000-0002-0752-7409

Faculdade Paulo Picanço, Brasil

E-mail: flaviatchemra@gmail.com

Márcia Rezende

ORCID: https://orcid.org/0000-0001-8474-5656 Faculdade Paulo Picanço, Brasil

E-mail: rezendemarcia@ outlook.com

Fernando Mendes Morelli

ORCID: https://orcid.org/0000-0001-9263-549X

Faculdade São Leopoldo Mandic, Brasil

E-mail: dr.fernandomorelli@gmail.com

Samara Tábata Cavalcante Braga Medeiros

ORCID: https://orcid.org/0000-0003-0650-7307

Faculdade Paulo Picanço, Brasil

E-mail: samaratabatacavalcante@hotmail.com

Antoniel Guimarães Diniz

ORCID: https://orcid.org/0000-0002-0056-5840

Faculdade São Leopoldo Mandic, Brasil E-mail: dr.agdiniz@gmail.com

\begin{abstract}
Resumo
A cirurgia de elevação do assoalho do seio maxilar apresenta-se como uma técnica com resultados previsíveis, sendo um procedimento comum da prática odontológica. Devido à grande diversidade e disponibilidade de substitutos ósseos, tem-se estudado cada vez mais sobre o material ideal para preencher a cavidade sinusal e, consequentemente, para a formação de um osso com características semelhantes ao do paciente em um menor período de tempo. A Fibrina Rica em Plaquetas (PRF) é um desses materiais que, por ser autólogo, apresentar baixo custo e um protocolo de obtenção simplificado, tem sido muito utilizado e tem apresentado excelentes resultados. Levando em consideração os benefícios atribuídos ao PRF, o objetivo desse estudo foi através de um relato de caso de boca dividida, avaliar clínica e histologicamente a sua efetividade quando associado a um substituto ósseo nas cirurgias de elevação do assoalho do seio maxilar, comparado ao uso exclusivo desse mesmo substituto. Apesar de não haver diferenças histológicas entre as amostras analisadas, a associação do PRF ao substituto ósseo melhorou a qualidade óssea na região enxertada quando comparada ao lado onde só foi utilizado o substituto ósseo como único material de enxertia.
\end{abstract}

Palavras-chave: Levantamento do assoalho do seio maxilar; Fibrina rica em plaquetas; Substitutos ósseos.

\begin{abstract}
Incluir o resumo em inglês. The sinus lift surgery is a common procedure with predictable outcomes in dental practice. There is a great diversity and availability of bone substitutes. Hence, the materials to fill the sinus cavity have been studied and searched due to the requirement for a patterned material with the capacity of bone formation in a short period of time. Platelet-rich fibrin (PRF) is one of those materials that, due to its autologous feature, has low cost and a simplified protocol. Therefore, it has been widely used and has shown excellent results. Considering the benefits attributed to PRF, the aim of this study was to evaluate the effectiveness of its association with a bone substitute in maxillary sinus lift surgeries, compared to the exclusive use of that same substitute. This split-mouth study was evaluated clinically and histologically. Despite the histological indifferences between the samples analyzed, the association of PRF with bone substitute improved bone quality in the grafted region when compared to the side where only the bone substitute was used.
\end{abstract}

Keywords: Sinus floor augmentation; Platelet-rich fibrin; Bone substitutes. 


\section{Resumen}

La cirugía de elevación de seno es un procedimiento común con resultados predecibles en la práctica dental. Existe una gran diversidad y disponibilidad de sustitutos óseos. De ahí que se hayan estudiado y buscado los materiales para rellenar la cavidad sinusal debido a la necesidad de un material estampado con capacidad de formación de hueso en un corto período de tiempo. La fibrina rica en plaquetas (PRF) es uno de esos materiales que, por su característica autóloga, tiene un bajo coste y un protocolo simplificado. Por tanto, ha sido ampliamente utilizado y ha mostrado excelentes resultados. Considerando los beneficios atribuidos a la PRF, el objetivo de este estudio fue evaluar la efectividad de su asociación con un sustituto óseo en cirugías de levantamiento de seno maxilar, en comparación con el uso exclusivo de ese mismo sustituto. Este estudio de boca dividida se evaluó clínica e histológicamente. A pesar de las indiferencias histológicas entre las muestras analizadas, la asociación del PRF con el sustituto óseo mejoró la calidad del hueso en la región injertada en comparación con el lado donde se utilizó únicamente el sustituto óseo.

Palabras clave: Elevación del seno maxilar; Fibrina rica en plaquetas, Sustitutos de hueso.

\section{Introdução}

Com a perda dos dentes posteriores superiores, ocorre a remodelação do osso alveolar causando a diminuição da espessura e altura do rebordo, resultante da pneumatização do seio maxilar e também da diminuição do suporte sanguíneo providenciada pela ausência do ligamento periodontal (Chappuis et al., 2013; Miron, Zucchelli, et al., 2017). Para que a reabilitação dessa região seja possível, foi necessário desenvolver uma técnica que conseguisse devolver volume ósseo suficiente para instalação de implantes.

A cirurgia de elevação do assoalho do seio maxilar tem como objetivo aumentar o volume ósseo na região que, além de insuficiente, apresenta qualidade desfavorável (Ali, Bakry, \& Abd-Elhakam, 2015). O procedimento tornou-se comum devido à simplicidade técnica e os bons resultados obtidos.

Atualmente, dispomos de duas técnicas cirúrgicas: a Técnica de Abertura da Janela Lateral e a Técnica de Elevação Atraumática do Seio Maxilar com Osteótomos de Summers, e o que define a técnica a ser utilizada é a quantidade de osso alveolar remanescente (Ortega-Mejia et al., 2020; Woo \& Le, 2004).

Para alcançar o resultado esperado, além de uma boa técnica cirúrgica e correta indicação, a escolha do material de enxertia é de fundamental importância para o sucesso do tratamento. O material de enxertia ideal deve obedecer aos seguintes requisitos: promover osteogênese; não apresentar resposta imunológica no hospedeiro; revascularizar rapidamente; estimular osteoindução; promover osteocondução e ser substituído completamente por osso em quantidade e qualidade semelhante ao do hospedeiro (Fardin et al., 2010; Gutierres et al., 2005). Esses materiais podem ser classificados de acordo com sua origem como autólogos, homógenos, heterógenos e sintéticos (Fardin et al., 2010; Rodolfo et al., 2017).

O osso autógeno é considerado padrão ouro para reconstrução dos processos alveolares atróficos pois além de apresentar os requisitos descritos acima (Ortega-Mejia et al., 2020; Tatullo et al., 2012), não apresenta risco de transmissão de doenças ou de possível rejeição, garantindo resultados clínicos mais previsíveis (Rodolfo et al., 2017). Porém apresentam a desvantagem de um procedimento cirúrgico adicional, o que acabou impulsionando o desenvolvimento de biomateriais (Basílio, de Lacerda, Vieira, de Lima Mendes, \& de Lacerda, 2018).

Os biomateriais poderão incorporar-se ao tecido durante o processo de cicatrização ou ser reabsorvido gradualmente pelos processos metabólicos do organismo, podendo ser homógeno/alógeno, xenógeno/heterógeno ou sintéticos/aloplásticos (Rodolfo et al., 2017). Eles são indicados de acordo com as suas características, porém podem apresentar algumas desvantagens de acordo com o material escolhido, como dificuldade de incorporação ao leito receptor, risco de transmissão de doenças, além de custo elevado. O custo-benefício de cada material deve ser levado em consideração pelo cirurgião quando da sua indicação (Fardin et al., 2010; Rodolfo et al., 2017).

Para melhorar a eficiência e acelerar a maturação do enxerto ósseo alveolar, diminuindo, assim, o tempo de cicatrização, entram em evidência a utilização dos hemoderivados devido à presença dos fatores de crescimento encontrados no sangue, mais especificamente nas plaquetas (Clark, 2001). 
A fibrina rica em plaquetas (PRF), obtida através da centrifugação do sangue do próprio paciente, é semelhante ao coágulo natural, favorecendo o processo de cicatrização e representando um sistema de liberação lenta de fatores de crescimento no intervalo de sete a 14 dias (Dohan et al., 2006; Miron, Zucchelli, et al., 2017). Por ser um enxerto autólogo, elimina o risco de transmissão de doenças, apresenta consistência gelatinosa que favorece a estabilidade do coágulo e do material enxertado, parece acelerar o processo fisiológico de cicatrização tecidual, reduz o volume de substituto ósseo (Choukroun et al., 2006; Tatullo et al., 2012; Wu et al., 2012). É indicado em procedimentos de elevação do assoalho do seio maxilar, preservação alveolar pós exodontia, recobrimento radicular em recessões gengivais, tratamento de defeitos ósseos e lesões periapicais e até para regeneração e revitalização pulpar (Khiste \& Naik Tari, 2013; Prakash, Thakur, \& surgery, 2011).

Levando em consideração as indicações e vantagens que o PRF tem apresentado, associado à facilidade da técnica e baixo custo de produção, esse estudo teve como objetivo avaliar a efetividade do uso do PRF nas cirurgias de elevação do seio maxilar, através de um relato de caso, no modelo de boca dividida, comparando clínica e histologicamente.

\section{Metodologia}

Trata-se de um relato de caso, caracterizado como um estudo descritivo, exploratório e com abordagem qualitativa (Pereira, Shitsuka, Parreira, \& Shitsuka, 2018).

Foram seguidos os princípios éticos de pesquisa envolvendo seres humanos, sendo preservada a identidade do voluntário e fornecido esclarecimentos sobre o tratamento. Iniciou-se os procedimentos clínicos somente após o paciente concordar e assinar o Termo de Consentimento Livre e Esclarecido (TCLE), consentindo o tratamento, a divulgação das imagens e de dados coletados durante o atendimento clínico e os que constavam no prontuário, sendo que o mesmo poderia desistir da participação no estudo a qualquer momento.

\section{Relato de caso}

O Paciente A.C.D., 59 anos, sexo masculino, leucoderma, diabético controlado (ASA 2), tinha como queixa principal a dificuldade de mastigação e a estética. Portador de prótese tipo protocolo inferior e prótese total no arco superior com estética e estabilidade comprometidas, apresentava hiperpneumatização dos seios maxilares e imagem sugestiva de cisto de retenção de muco bilateral (Figura 1).

Figura 1 - Tomografia computadorizada Cone Bean de maxila total.

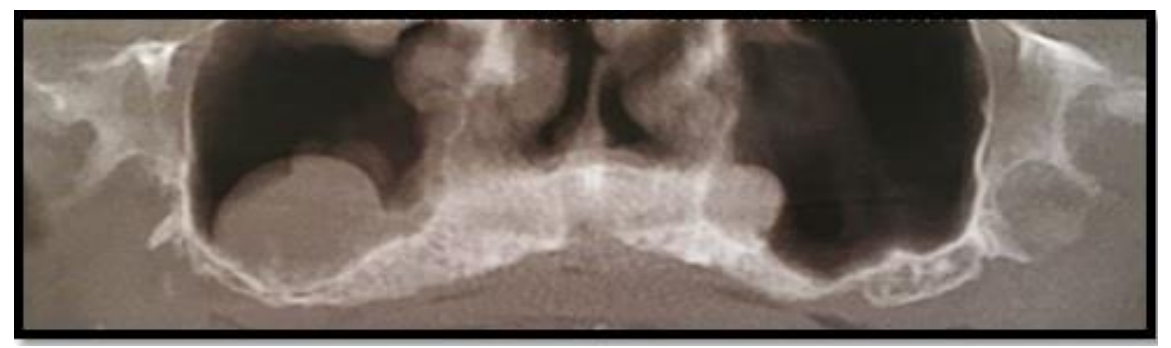

Fonte: Autores.

Após exames laboratoriais dentro da normalidade e tomografia computadorizada Cone Bean de maxila total para planejamento de cirurgia de enxertia, foi encaminhado ao médico otorrinolaringologista para avaliação e conduta dos cistos, sendo tratado com Amoxicilina 500 mg + Ácido Clavulânico 125 mg (EMS, São Paulo, Hortolândia, Brasil) por sete dias (um comprimido a cada oito horas) e liberado para a realização do procedimento.

Foi proposta cirurgia bilateral de elevação do assoalho do seio maxilar utilizando, do lado esquerdo, o enxerto ósseo 
liofilizado associado ao PRF e, do lado direito, somente o enxerto ósseo, para posterior instalação de implantes, possibilitando, assim, avaliarmos a efetividade do uso da PRF (Figura 2).

Figura 2 - Material de enxertia. A: sangue colhido para produção do PRF e osso liofilizado; B: membranas de PRF; C: Stickybone.

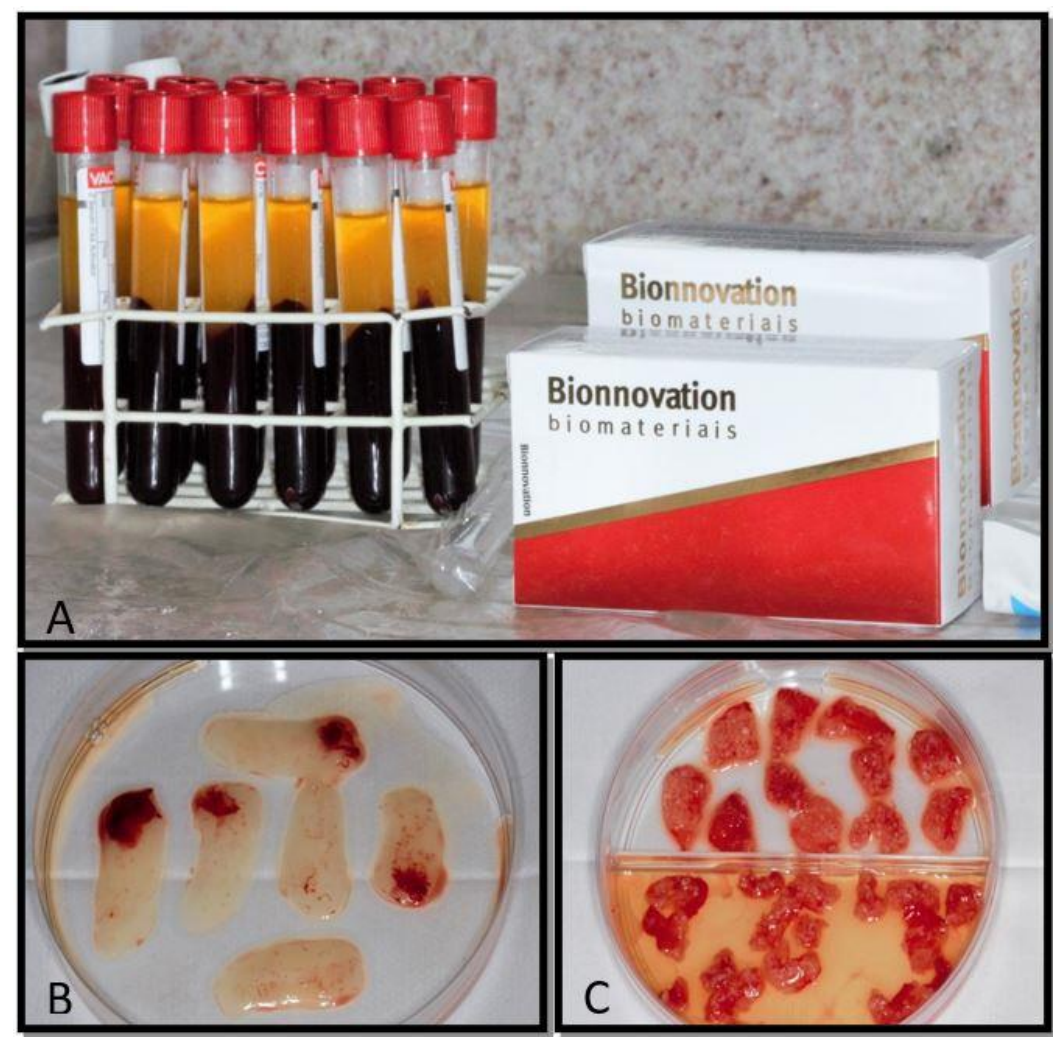

Fonte: Autores.

O paciente foi esclarecido sobre os procedimentos aos quais seria submetido, não apresentando nenhuma dúvida, e após assinatura do termo de consentimento livre e esclarecido, a cirurgia foi agendada. Foi prescrito como medicação préoperatória dois comprimidos de Amoxicilina $500 \mathrm{mg}$ e dois comprimidos de Dexametasona $4 \mathrm{mg}$ (EMS, São Paulo, Hortolândia, Brasil) uma hora antes da cirurgia.

No dia da cirurgia, após aferir a pressão do paciente $(120$ x $80 \mathrm{mmHg})$, foi realizada a coleta sanguínea para obtenção do PRF previamente à cirurgia. Devido à extensão do seio maxilar do paciente, foram colhidos 14 tubos de sangue. Dos 14 tubos, dois foram imediatamente centrifugados a $700 \mathrm{rpm}$ (aproximadamente $60 \mathrm{~g}$ ) por três minutos para obtenção do i-PRF (PRF injetável) e 12 foram imediatamente centrifugados a $3000 \mathrm{rpm}$ (aproximadamente $400 \mathrm{~g}$ ) por 10 minutos para obtenção das membranas de PRF, conforme os protocolos descritos por Dohan et al. (2006) e Miron, Fujioka-Kobayashi, et al. (2017) respectivamente, para obtenção do sticky-bone. Enquanto os procedimentos de centrifugação e preparo eram executados, a mesa cirúrgica foi preparada e, após paramentação da equipe e paciente, iniciou-se a cirurgia.

Optou-se por realizar a abertura de um seio por vez devido à extensão do mesmo, iniciando pelo lado direito. Paciente realizou bochecho por 1 minuto com Solução de Gluconato de Clorexidina, 0,12\% foi anestesiado com seis tubetes de Mepivacaína 2\% associado a Epinefrina 1:100.000 em fundo de sulco e crista óssea alveolar. Com o auxílio de uma lâmina de bisturi número 15 , realizou-se uma incisão crestal de pilar canino até segundo molar, com relaxantes anterior e posterior. Foi realizado o descolamento do retalho mucoperiostal, seguida da demarcação da janela de acesso com broca esférica diamantada número 06 e osteotomia com broca esférica diamantada número 08 (KG Sorensen, São Paulo, Cotia, Brasil) (Figura 3). 
Figura 3 - Rebordo maxilar. A: rebordo maxilar previamente à cirurgia; B: retalho lado direito; C: retalho lado esquerdo.

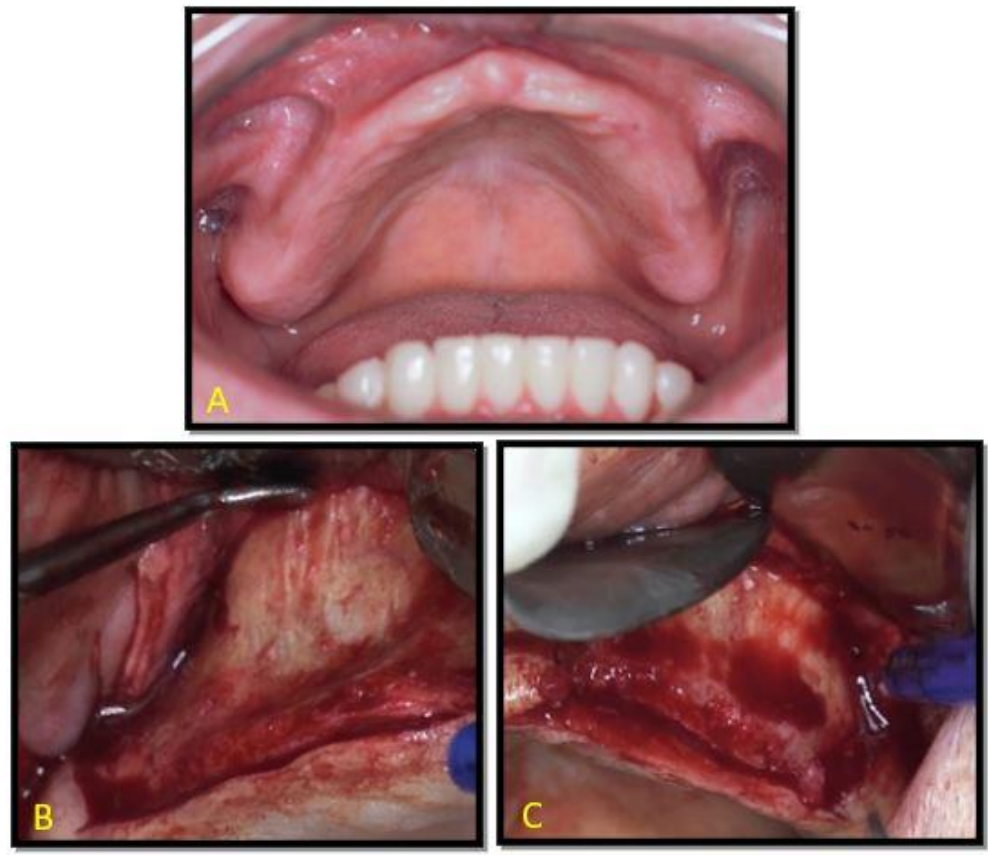

Fonte: Autores.

Após completar a osteotomia, com a ajuda de curetas específicas, a membrana sinusal foi descolada de forma gradativa, através da parede lateral, no sentido da parede inferior, anterior e posterior do seio maxilar sendo, em seguida, deslocada delicadamente no sentido da parede medial, mantendo-a posicionada o mais superior possível, de forma a manter o espaço para colocação do material de enxertia (Figura 4).

Figura 4 - A: Ostetomia janela lateral direita; B: Osteotomia janela lateral esquerda.

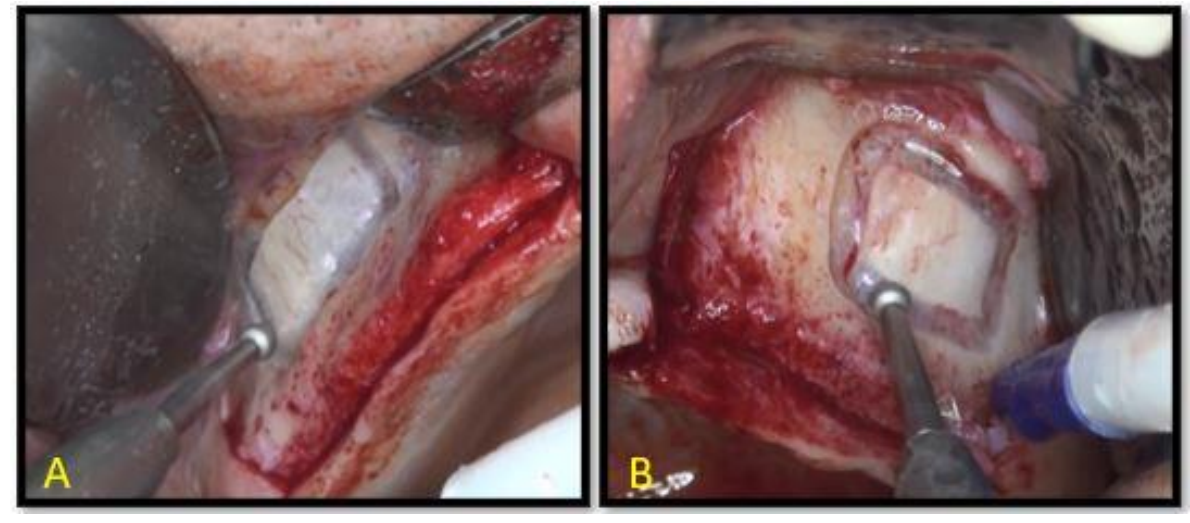

Fonte: Autores.

Não foi observado perfuração da membrana de Schneider em ambos os lados durante o movimento normal de respiração do paciente. Com a membrana reposicionada e mantida na nova posição com o auxílio de uma cureta, as cavidades foram então preenchidas cada uma com $2 \mathrm{~g}$ de osso liofilizado. Do lado direito, utilizamos apenas o Bonefill Porous grosso (Bionnovation, São Paulo, Bauru, Brasil) aglutinado com soro fisiológico a 0,9\%. Já do lado esquerdo, utilizamos o Bonefill Porous grosso (Bionnovation, São Paulo, Bauru, Brasil) associado ao i-PRF e às membranas picotadas, formando o stickybone (Figura 5). 
Figura 5 - Inserção do material de enxertia no seio maxilar. A: osso liofilizado; B: Sticky-bone e membranas de PRF.

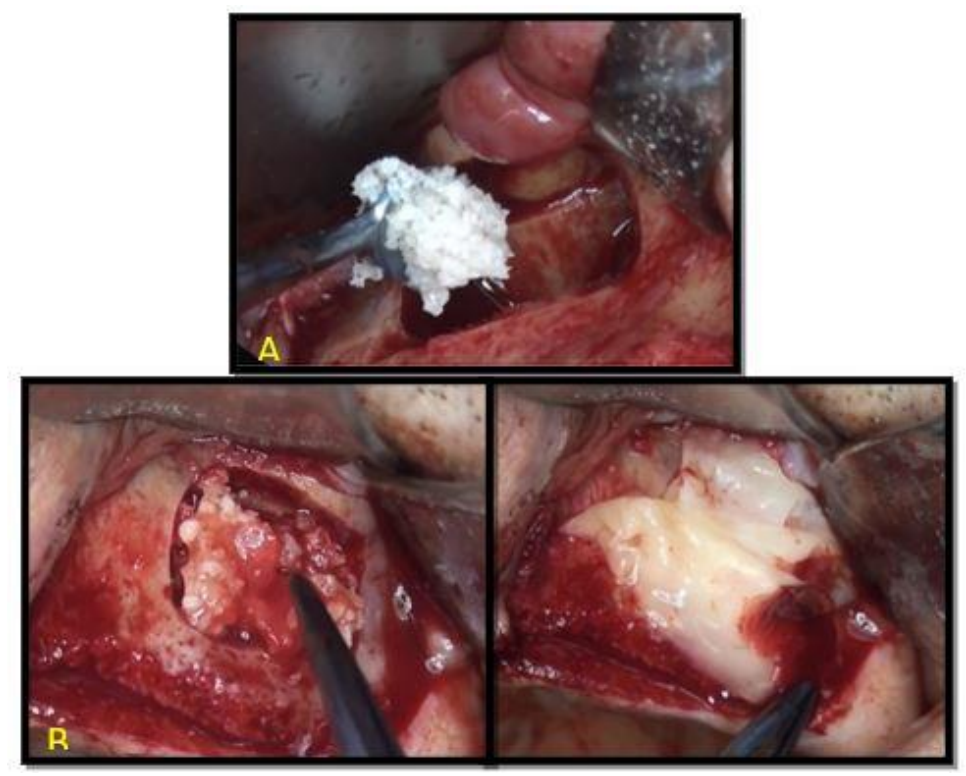

Fonte: Autores.

Do lado direito, optou-se por não recobrir a janela de acesso com membrana de colágeno enquanto, do lado esquerdo, a janela foi recoberta com as membranas de PRF. Os retalhos foram reposicionados e suturados com fio de nylon (Figura 6).

Figura 6 - Sutura.

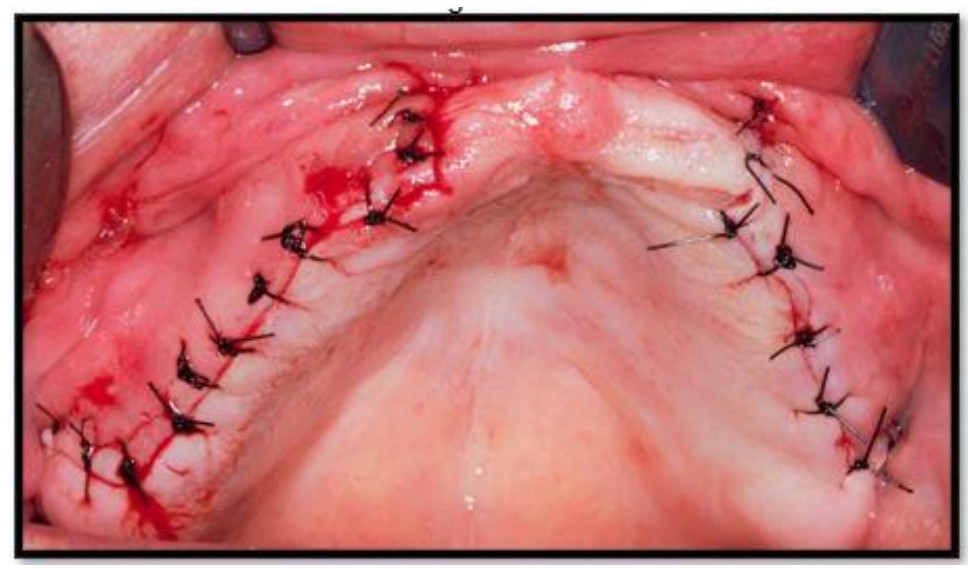

Fonte: Autores.

Como medicação pós-operatória foi prescrito um comprimido a cada oito horas de Amoxicilina 500 mg + Ácido Clavulânico $125 \mathrm{mg}$, um comprimido a cada 12 horas por cinco dias de Cetroprofeno 100 mg (Medley, São Paulo, Campinas, Brasil) e um comprimido sublingual a cada oito horas por três dias de Toragesic 10mg (EMS, São Paulo, Hortolândia, Brasil) e orientado quanto aos cuidados pós-operatórios.

A prótese total superior foi aliviada e reembasada com resina macia Soft Confort (Dencril, São Paulo, Pirassununga, Brasil) evitando compressão da região operada. A remoção de suturas foi realizada após sete dias. Paciente não referiu nenhuma intercorrência no pós-operatório.

Após seis meses da cirurgia de enxertia foi realizada nova tomografia para avaliação e planejamento de implantes, sendo então planejado a instalação de seis implantes e a remoção de amostras para exame histológico (Figura 7). 
Figura 7 - Tomografia computadorizada Cone Bean de maxila total após seis meses da cirurgia de enxertia.

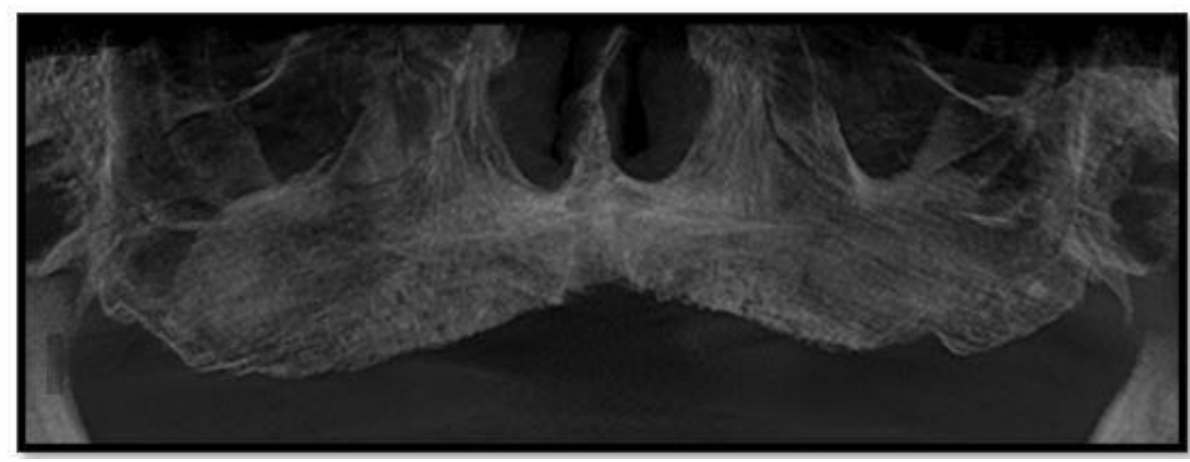

Fonte: Autores.

Após anestesia com 6 tubetes de Mepivacaína 2\% associado a Epinefrina 1:100.000 em fundo de sulco, crista do rebordo e palatina em toda a extensão da maxila, realizou-se incisão de túber a túber e descolamento e deslocamento do retalho mucoperiostal (Figura 8).

Figura 8 - Retalho mucoperiostal de túber a túber.

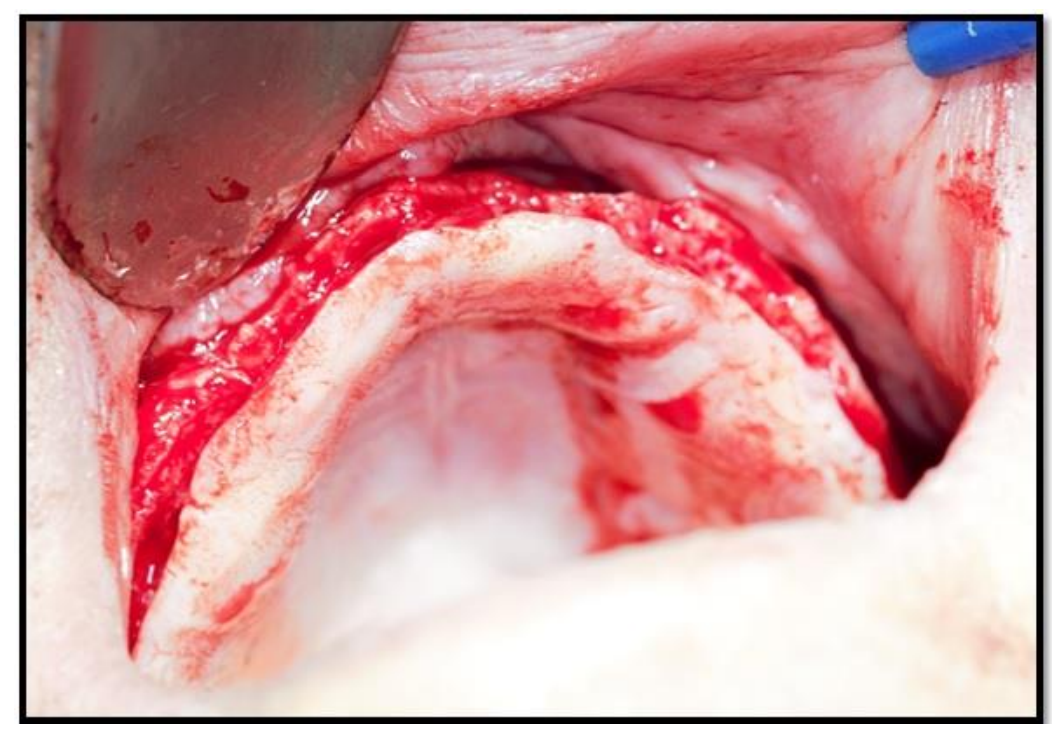

Fonte: Autores.

$\mathrm{Na}$ região onde foi realizado o acesso ao seio maxilar, foram colhidas amostras com trefinas de 2 mm na interface entre a janela realizada e o osso maxilar. Estas amostras foram imediatamente colocadas em solução de formol (10\%) e enviadas para exame histológico (Figura 9). 
Figura 9 - A: trefina 2mm utilizada para remoção de amostra para exame histológico; B: esquema do local de remoção da amostra da região enxertada à direita; C: esquema do local de remoção da amostra da região enxertada à esquerda.

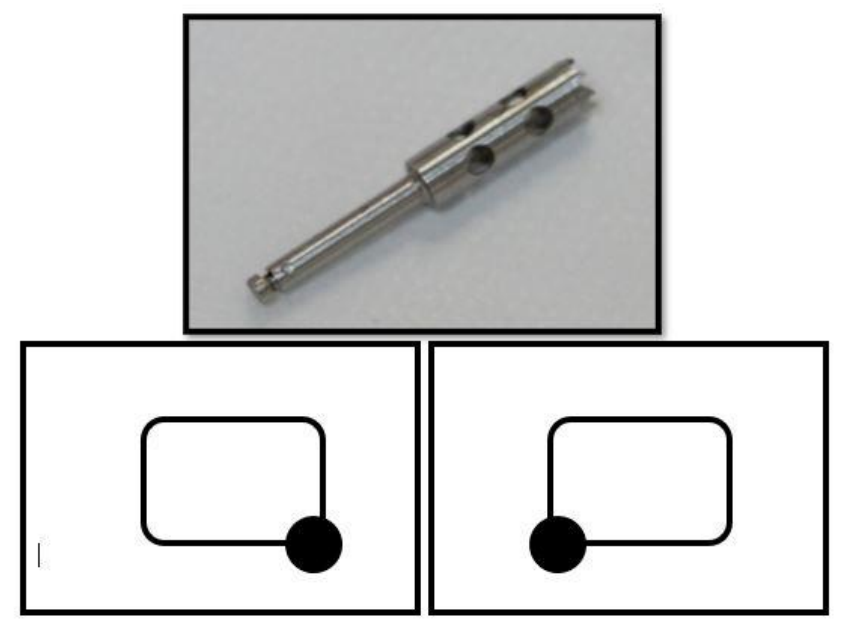

Fonte: Autores.

A cirurgia seguiu com as perfurações para os implantes, notando-se desde já a boa resistência óssea. Prosseguiu-se com a instalação de seis implantes Alvim Cone Morse (Neodent, São Paulo, São Paulo, Brasil), sendo três implantes com medidas de $3.5 \times 10 \mathrm{~mm}$, um implante com medida de $3.5 \times 11.5 \mathrm{~mm}$ e dois implantes com medidas de $4.3 \times 13 \mathrm{~mm}$, todos com travamento entre 32 e 45 Newtons, e sutura com nylon (Figura 10).

Após três meses da cirurgia de instalação de implantes e coleta de amostra para exame histológico, o paciente retornou com radiografia panorâmica para controle e avaliação do posicionamento dos implantes (Figura 11).

O laudo do exame histológico não apontou diferenças entre as amostras colhidas. Ambas amostras revelam a presença de material exógeno mineralizado semelhante a tecido ósseo e formação de tecido ósseo vital na periferia, contendo osteócitos em lacunas e osteoblastos periféricos.

Figura 10 - Sequência cirúrgica. A: perfuração; B: Verificação do paralelismo entre as perfurações; C: Instalação dos implantes; D: Implantes instalados.

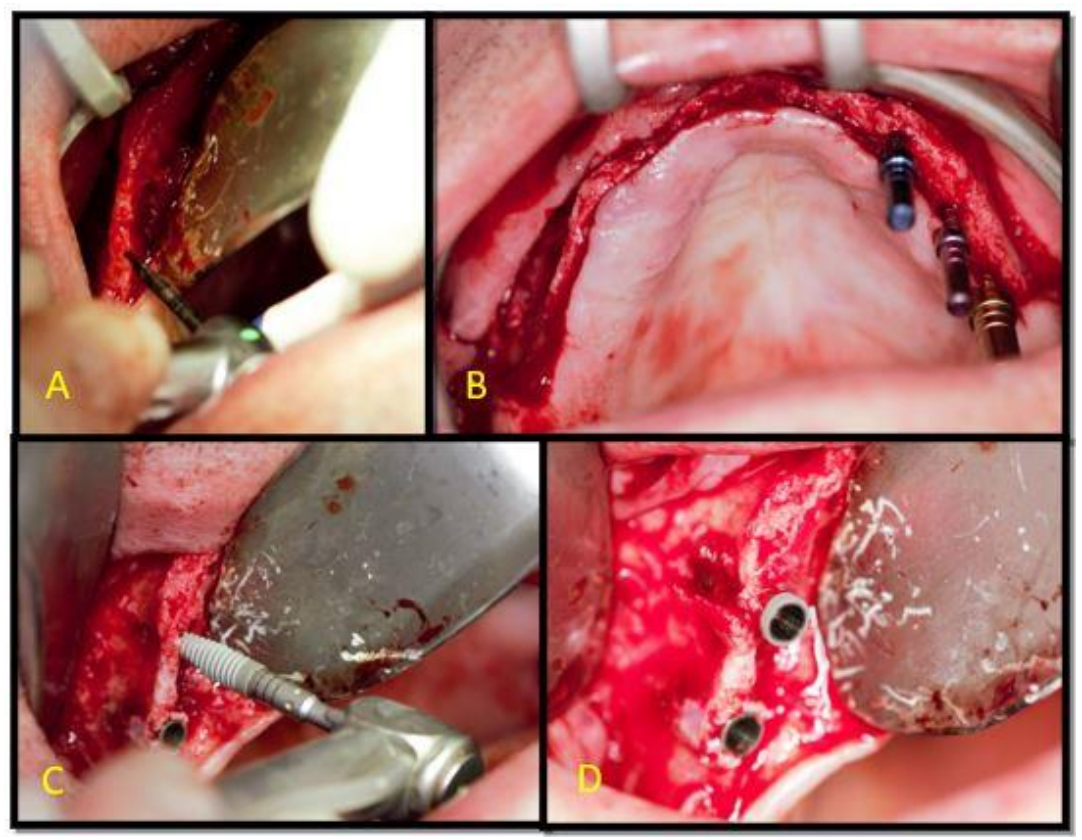

Fonte: Autores. 
Figura 11 - Radiografia panorâmica após 3 meses da colocação dos implantes.

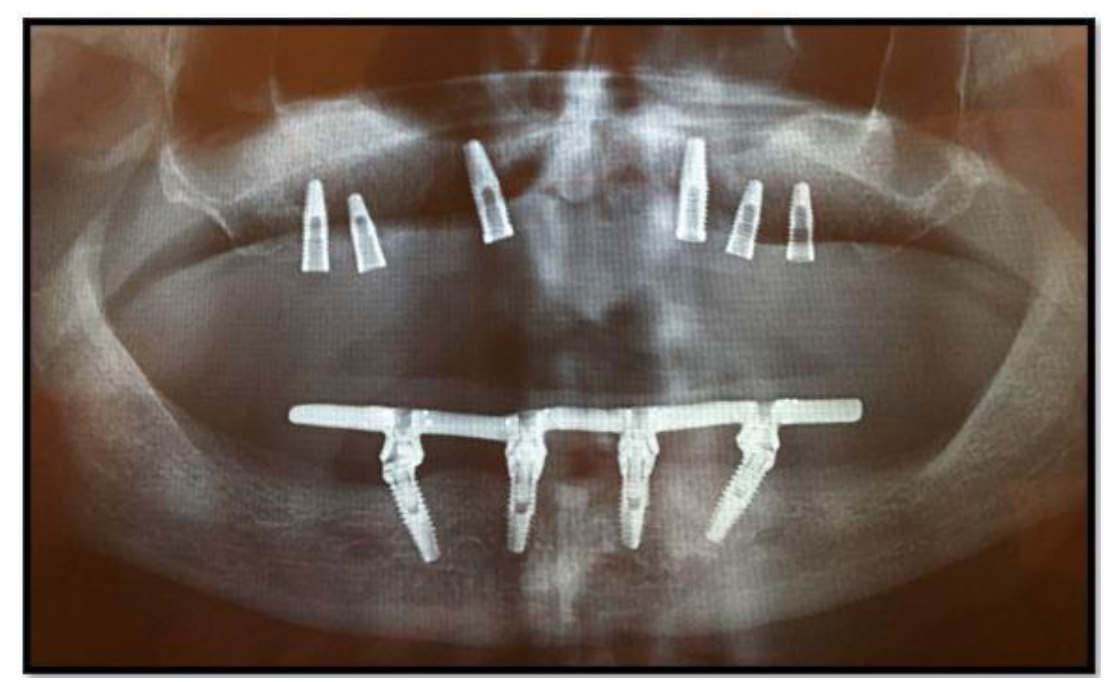

Fonte: Autores.

Paciente foi orientado a retornar seis meses após a instalação dos implantes para reabertura dos implantes e início da fase protética.

\section{Discussão}

$\mathrm{Na}$ literatura, é evidente a eficácia do uso de diferentes biomateriais no interior do seio maxilar (Al-Moraissi et al., 2020; Basílio et al., 2018; Browaeys, Bouvry, De Bruyn, \& research, 2007; Danesh-Sani, Engebretson, \& Janal, 2017; Simonpieri, Choukroun, Del Corso, Sammartino, \& Ehrenfest, 2011). O PRF tem sido comumente associado a esses biomateriais com intuito de melhorar a eficiência e acelerar a maturação do enxerto ósseo diminuindo o tempo de cicatrização (Ali et al., 2015).

Diversos estudos mostram que a combinação do osso autógeno com o PRF na cirurgia de elevação do assoalho do seio maxilar tem obtido grandes sucessos. Entretanto, devido à morbidade do procedimento de remoção do osso autólogo, os substitutos ósseos xenógenos ou sintéticos têm sido cada vez mais utilizados (Santos et al., 2017; Tatullo et al., 2012; Zhang et al., 2012).

Enxertos xenógenos causam processos fisiológicos de remodelação óssea envolta do implante, com neoaposição e ganho ósseo significante graças a características físicas e químicas que são muito próximas do osso humano. Em associação com o PRF, o osso xenógeno é um substituto ósseo mais adequado para o levantamento de seio maxilar devido ao tempo de reabsorção mais lento se comparado ao osso autógeno, proporcionando maior manutenção do enxerto (Santos et al., 2017).

No presente estudo, corroborando com os relatos de Tatullo et al. (2012) e Santos et al. (2017), tanto a associação do osso xenógeno (Bonefill, Bionnovation) ao PRF como a utilização do osso como único material de enxertia, mostraram bons resultados, com bons ganhos ósseos. Entretanto, após o período de seis meses para instalação dos implantes, é notável a diferença na qualidade do osso formado, sendo que, no lado esquerdo, onde o osso liofilizado foi associado ao PRF, o osso apresentou uma maior resistência à perfuração (observação clínica), sendo bastante semelhante ao osso do paciente. Já do lado direito, onde só utilizamos o substituto ósseo, a qualidade do osso se mostrou bastante inferior, sendo necessária a subfresagem para favorecer a travamento dos implantes instalados. É importante ressaltar que alguns estudos mostram que a associação do PRF ao osso liofilizado possibilita a instalação dos implantes após apenas quatro meses da cirurgia de enxertia, enquanto que os seis meses aguardados nesse estudo não foram suficientes para que o lado abordado somente com o osso liofilizado apresentasse características semelhantes ao osso do paciente, demonstrando a necessidade de um tempo ainda maior para 
obtenção de um osso com a mesma qualidade.

Outra diferença importante foi observada durante o descolamento do retalho. Enquanto do lado esquerdo o retalho foi descolado com facilidade, apresentando diferença evidente entre tecido ósseo e tecido mole, do lado direito não foi possível observar essa separação já que o tecido mole e tecido ósseo se confundiam na região do acesso ao seio, dificultando o descolamento do retalho. Esse achado vai de encontro aos relatos de Gassling et al. (2013), que sugerem que o recobrimento da janela de acesso com uma membrana poderia melhorar a qualidade do osso nessa área já que eles supõem que a formação óssea começa pelas paredes e assoalho do seio e é finalizada na parede lateral onde foi realizada a osteotomia. O recobrimento da janela lateral com membrana ainda teria um efeito positivo na formação de osso vital no levantamento de seio comparado a não cobertura, existindo três possíveis explicações para isso: primeiro, a membrana ajuda a prevenir o deslocamento do material enxertado; segundo, a membrana age como uma proteção contra a invasão de tecidos moles; e terceiro, propriedades específicas da membrana podem ajudar a formação de osso vital na área enxertada.

Em relação à área de eleição para colher a amostra desse estudo para análise histológica, uma vez que a parede lateral é a última área a mineralizar, a mesma seria um ótimo local para biópsia para avaliação da qualidade do enxerto ósseo (Gassling et al., 2013).

Apesar da nítida diferença de resistência óssea durante a coleta das amostras e perfuração para os implantes, o laudo histológico do material não mostrou diferença entre as amostras, levando a concluir que, a médio e longo prazo, a diferença entre as regiões enxertadas é estatisticamente insignificante, sendo mais evidente somente na fase inicial, onde a presença do PRF acelera o início do processo de reparação. Entretanto, assim como Tatullo et al. (2012) já haviam relatado, a qualidade óssea encontrada do lado onde foi utilizado o PRF leva a crer que o tempo de regeneração e reparo tecidual foi menor, podendo-se concluir que os implantes poderiam ter sido instalados com menor tempo de espera.

\section{Considerações Finais}

Apesar de não haver diferenças histológicas entre as amostras analisadas, a associação do PRF ao substituto ósseo melhorou a qualidade óssea na região enxertada quando comparada ao lado onde só foi utilizado o substituto ósseo como único material de enxertia.

Sugere-se que mais pesquisas sejam realizadas para avaliar a possibilidade de redução no tempo de espera entre a enxertia e a instalação dos implantes, para verificar a efetividade do PRF associado a outros materiais de enxertia e para comprovar a efetividade apresentada neste relato de caso.

\section{Referências}

Al-Moraissi, E., Alkhutari, A., Abotaleb, B., Altairi, N., \& Del Fabbro, M. (2020). Do osteoconductive bone substitutes result in similar bone regeneration for maxillary sinus augmentation when compared to osteogenic and osteoinductive bone grafts? A systematic review and frequentist network meta-analysis. International journal of oral and maxillofacial surgery, 49(1), 107-120.

Ali, S., Bakry, S. A., \& Abd-Elhakam, H. (2015). Platelet-rich fibrin in maxillary sinus augmentation: a systematic review. Journal of Oral Implantology, 41(6), 746-753.

Basílio, J. C. S., de Lacerda, E. J. R., Vieira, M. V. S., de Lima Mendes, H., \& de Lacerda, L. J. R. (2018). Análise Histológica de Levantamento de Seio Maxilar Utilizando Biomaterial Xenógeno Versus Sintético+ L-Prf (Fibrina Rica em Plaquetas e Leucócitos). The International Journal of Oral and Maxillofacial Implants, 1:25-9.

Browaeys, H., Bouvry, P., \& De Bruyn, H. (2007). A literature review on biomaterials in sinus augmentation procedures. Clin Implant Dent Relat Res, 9(3), $166-177$.

Chappuis, V., Engel, O., Reyes, M., Shahim, K., Nolte, L.-P., \& Buser, D. (2013). Ridge alterations post-extraction in the esthetic zone: a 3D analysis with CBCT. Journal of Dental Research, 92(12_suppl), 195S-201S.

Choukroun, J., Diss, A., Simonpieri, A., Girard, M.-O., Schoeffler, C., Dohan, S. L., Mouhyi, J., \& Gogly, B. (2006). Platelet-rich fibrin (PRF): a secondgeneration platelet concentrate. Part IV: clinical effects on tissue healing. Oral Surgery, Oral Medicine, Oral Pathology, and Oral Radiology, 101(3), e56-e60. 
Clark, R. A. (2001). Fibrin and wound healing. Annals of the New York Academy of Sciences, 936, 355.

Danesh-Sani, S., Engebretson, S. P., \& Janal, M. N. (2017). Histomorphometric results of different grafting materials and effect of healing time on bone maturation after sinus floor augmentation: a systematic review and meta-analysis. Journal of Periodontal Research, 52(3), 301-312.

Dohan, D. M., Choukroun, J., Diss, A., Dohan, S. L., Dohan, A. J., Mouhyi, J., \& Gogly, B. (2006). Platelet-rich fibrin (PRF): a second-generation platelet concentrate. Part I: technological concepts and evolution. Oral Surg Oral Med Oral Pathol Oral Radiol Endod, 101(3), e37-e44.

Fardin, A. C., Jardim, E. C. G., Pereira, F. C., Guskuma, M. H., Aranega, A. M., \& Garcia Júnior, I. R. (2010). Enxerto ósseo em odontologia: revisão de literatura. Innovations Implant Journal, 5(3), 48-52.

Gassling, V., Purcz, N., Braesen, J.-H., Will, M., Gierloff, M., Behrens, E., Açil, Y., \& Wiltfang, J. (2013). Comparison of two different absorbable membranes for the coverage of lateral osteotomy sites in maxillary sinus augmentation: a preliminary study. Journal of Cranio-Maxillo-Facial Surgery, 41(1), 76-82.

Gutierres, M., Lopes, M. A., Hussain, N. S., Cabral, A. T., Almeida, L., \& Santos, J. D. J. A. (2005). Substitutos Ósseos: conceitos gerais e estado actual. Arquivos de medicina, 19(4), 153-162.

Khiste, S. V., \& Tari, R. N. (2013). Platelet-rich fibrin as a biofuel for tissue regeneration. ISRN Biomaterials.

Miron, R. J., Fujioka-Kobayashi, M., Hernandez, M., Kandalam, U., Zhang, Y., Ghanaati, S., \& Choukroun, J. (2017). Injectable platelet rich fibrin (i-PRF): opportunities in regenerative dentistry? , Clinical Oral Investigations, 21(8), 2619-2627.

Miron, R. J., Zucchelli, G., Pikos, M. A., Salama, M., Lee, S., Guillemette, V., et al. (2017). Use of platelet-rich fibrin in regenerative dentistry: a systematic review. Clinical Oral Investigations, 21(6), 1913-1927.

Ortega-Mejia, H., Estrugo-Devesa, A., Saka-Herrán, C., Ayuso-Montero, R., López-López, J., \& Velasco-Ortega, E. J. M. (2020). Platelet-Rich Plasma in Maxillary Sinus Augmentation: Systematic Review. Materials (Basel), 13(3), 622.

Pereira, A., Shitsuka, D., Parreira, F., \& Shitsuka, R. (2018). Metodologia da pesquisa científica. Santa Maria.

Prakash, S., \& Thakur, A. (2011). Platelet concentrates: past, present and future. Journal of Oral and Maxillofacial Surgery, 10(1), 45-49.

Rodolfo, L. M., Machado, L. G., Betoni-Júnior, W., Faeda, R. S., Queiroz, T. P., \& de Souza Faloni, A. P. S. (2017). Substitutos ósseos alógenos e xenógenos comparados ao enxerto autógeno: reações biológicas. Revista Brasileira Multidisciplinar, 20(1), 94-105.

Santos, D. D. D. d., de Omena Fragoso, F. C., de Lima Netto, T. J., da Silva Oliveira, E., de Brito, W. T. P., da Silva, C. P., \& Cavalcanti, T. C. J. R. d. A.-I.-. (2017). Uso dos concentrados plaquetários rico em fibrina e leucócitos (L-PRF) na cirurgia de levantamento de seio maxilar. Revista da AcBO, 6(2).

Simonpieri, A., Choukroun, J., Del Corso, M., Sammartino, G., \& Ehrenfest, D. M. D. J. I. d. (2011). Simultaneous sinus-lift and implantation using microthreaded implants and leukocyte-and platelet-rich fibrin as sole grafting material: a six-year experience. Implant Dentistry, 20(1), 2-12.

Tatullo, M., Marrelli, M., Cassetta, M., Pacifici, A., Stefanelli, L. V., Scacco, S., \& Inchingolo, F. J. (2012). Platelet Rich Fibrin (PRF) in reconstructive surgery of atrophied maxillary bones: clinical and histological evaluations. International Journal of Medical Sciences, 9(10), 872.

Woo, I., \& Le, B. J. (2004). Maxillary sinus floor elevation: review of anatomy and two techniques. Implant Dentistry, 13(1), 28-32.

Wu, C. L., Lee, S. S., Tsai, C. H., Lu, K. H., Zhao, J. H., \& Chang, Y. C. (2012). Platelet-rich fibrin increases cell attachment, proliferation and collagen-related protein expression of human osteoblasts. Australian Dental Journal, 57(2), 207-212.

Zhang, Y., Tangl, S., Huber, C. D., Lin, Y., Qiu, L., \& Rausch-Fan, X. (2012). Effects of Choukroun's platelet-rich fibrin on bone regeneration in combination with deproteinized bovine bone mineral in maxillary sinus augmentation: a histological and histomorphometric study. Journal of Cranio-Maxillofacial Surgery, 40(4), 321-328. 